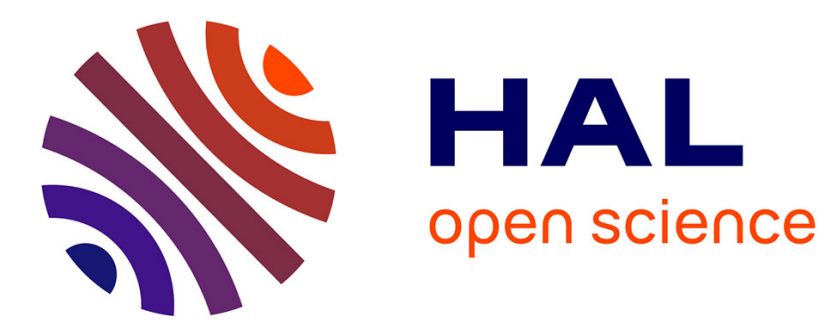

\title{
Disorder induced in silicon carbide by heavy-ion irradiation \\ Jean-Marc Costantini
}

\section{To cite this version:}

Jean-Marc Costantini. Disorder induced in silicon carbide by heavy-ion irradiation. Philosophical Magazine Letters, 2021, https://doi.org/10.1080/09500839.2021.1884302. 10.1080/09500839.2021.1884302 . cea-03186649

\section{HAL Id: cea-03186649 https://hal-cea.archives-ouvertes.fr/cea-03186649}

Submitted on 31 Mar 2021

HAL is a multi-disciplinary open access archive for the deposit and dissemination of scientific research documents, whether they are published or not. The documents may come from teaching and research institutions in France or abroad, or from public or private research centers.
L'archive ouverte pluridisciplinaire HAL, est destinée au dépôt et à la diffusion de documents scientifiques de niveau recherche, publiés ou non, émanant des établissements d'enseignement et de recherche français ou étrangers, des laboratoires publics ou privés.

\section{(ㅇ)(1) $\$$}

Distributed under a Creative Commons Attribution - NonCommercial - NoDerivatives $\mid 4.0$ 
Disorder induced in silicon carbide by heavy-ion irradiation

Jean-Marc COSTANTINI ${ }^{1}$,

Université Paris-Saclay, CEA, Service de Recherches Métallurgiques Appliquées, 91191, Gif-surYvette, France

PACS numbers: $61.80 . J h ; 61.43 . E r ; 78.40 .-q$

\section{ABSTRACT}

The decrease of crystal phonon peak intensities in Raman spectra of silicon carbide after heavy-ion irradiation is analyzed in relation to band-gap shrinkage and Urbach edge increase arising from accumulation of lattice disorder. The discrepancy on amorphous fractions deduced from Raman spectroscopy and Rutherford backscattering-channeling spectroscopy is addressed by taking into account the point defect formation and amorphization by displacement damage. A new analysis of Raman data is provided on the basis of the scattered light self-absorption due to damage build-up.

\footnotetext{
${ }^{1}$ Corresponding author's email : jean-marc.costantini@cea.fr
} 


\section{INTRODUCTION}

Many studies have shown that amorphization (loss of long-range atomic order) of silicon carbide (SiC) is resulting from accumulation of point defects (Frenkel pairs and anti-site defects) and defectcluster formation above a threshold irradiation dose (or fluence) upon energetic electron [1] or ion [2] irradiations. Rutherford backscattering spectrometry and channeling (RBS/C) data have actually shown that complete amorphization of SiC is achieved in two steps in agreement with Molecular Dynamics (MD) simulations [3]: a first step corresponds to defect accumulation (to reach amorphization) and a second one of amorphous domain overlap [4-6]. No direct amorphization is achieved by a single ion impact in SiC. The progressive loss of long-range order is also seen by the vanishing of the narrow Raman peaks associated to phonon modes of a given polytype [7-8]. This corresponds to an increase of the backscattering yield in RBS/C experiments, corresponding to disorder in the Si sublattice [7-9].

Raman spectra of the amorphous phase (a-SiC) show the growth of broad side bands assigned to $\mathrm{Si}-\mathrm{Si}$ and $\mathrm{C}-\mathrm{C}$ bonds, but also distorted/disordered Si-C vibration modes, which do not exist in the parent crystalline phase $[7,8,10,11]$. This means that a chemical disorder has been created upon amorphization, in agreement with EXAFS data [11]. The short-range chemical disorder (given by the growth of the broad side bands) was correlated to the long-range disorder (given by the vanishing of narrow phonon peaks) along a three-stage process [7-8]. The stage I of defect accumulation in this process is consistent with the above-mentioned first step of point-defect accumulation seen by RBS/C spectrometry. However, a clear deviation was seen between these two sets of data [6], as found for $50-\mathrm{keV} \mathrm{Ga}$ ion irradiation of $6 \mathrm{H}-\mathrm{SiC}$ in the same fluence range [12]. Raman spectroscopy is apparently more sensitive to low damage than RBS/C: it gives a larger disordered fraction than RBS/C in the first stage. Our aim in the present paper is to address this deviation between Raman spectroscopy data and RBS/C spectrometry data in ion-irradiated hexagonal silicon carbide.

The Relative Raman intensity (RRI) variation was used to follow the irradiation damage in SiC [7, 8, 13]. This RRI index is based on the decrease of the Raman peak intensities which is directly connected to the increase of the optical absorption. It reflects the long-range disorder into the crystal, even though there is no straightforward relationship between the RRI index and the lattice disorder fraction. The total disorder $\left(1-A_{\text {norm }}\right)$ was deduced from the total area $A$ under the principal firstorder Raman lines normalized to the value $A_{\text {cryst }}$ of the crystalline material $\left(A_{\text {norm }}=A / A_{\text {cryst }}\right)[7,8,12$, 13].

Fist-order Raman peaks for frequencies between $750 \mathrm{~cm}^{-1}$ and $1000 \mathrm{~cm}^{-1}$ correspond to the transverse (TO) and longitudinal (LO) optical phonons at the first Brillouin zone (BZ) center ( $\Gamma$ point) for a zero momentum transfer $(q=0)[14]$. Actually, the classical selection rules of periodic solids using the lattice-vibration wave vector are broken in a disordered solid [15-17]. Therefore, the folded phonon density-of-states (DOS) at the $\Gamma$ point involves contributions of vibration modes of various symmetry labels from other points of the BZ [15]. In principle, it is challenging to monitor the decrease of long-range order by the decrease in intensity of a specific phonon peak owing to the overlap of these contributions for the same phonon energies (i.e. same Raman shifts).

The main concern is the discrepancy between the two techniques: what makes Raman spectroscopy more sensitive than RBS/C in the first step of damage? In this respect, it is known that point defects induce localized electronic levels (in stage I), and long-range disorder generates band tails of 
electronic extended states in the band gap (in stage II) [18]. This, in turn, may induce an increase of self-absorption of Raman lines (for a laser line at photon energy $E \sim 2.3 \mathrm{eV}$ ). Indeed, we have brought evidence from UV-visible absorption spectra of a clear shrinkage of the optical gap energy $\left(E_{G}\right)$ from $\sim 3 \mathrm{eV}$ to $0.5 \mathrm{eV}$, and increase of the Urbach energy $\left(\mathrm{E}_{\mathrm{u}}\right)$, with the irradiation dose, until saturation is reached for the amorphous phase $[7,8,19]$. Such large band-gap shrinkage is attributed to the strong disorder with homonuclear $\mathrm{Si}-\mathrm{Si}$ and $\mathrm{C}-\mathrm{C}$ "wrong bonds" induced in the amorphous phase. Henceforth, self-absorption of the scattered light inside the damaged layer must be taken into account.

\section{DISCUSSION}

Let us consider, first of all, the intensity of emitted scattered light $\left(I_{s}\right)$ measured from the probed sample depth (d), and denote as $\alpha$ the absorption coefficient for the photon energy ( $\hbar \omega=E$ ) of the excitation laser light. For an attenuation of the scattered light by $\sim 60 \%$, we have $d \sim 1 / \alpha$. The probed thickness will decrease with $E_{G}$, since in the absorption edge region for indirect gap absorption in the case of $\mathrm{SiC}, \alpha$ writes:

$$
\alpha=\alpha_{0} \exp \left(\frac{E_{G}-\hbar \omega}{E_{U}}\right)
$$

where $\alpha_{0}$ is a constant $[20,21]$. For a-SiC, we have $\alpha \sim 80,000 \mathrm{~cm}^{-1}$ at the wavelength of $500 \mathrm{~nm}$ (E $\sim 2.5 \mathrm{eV})[7,8]$, that gives a probed depth of $\mathrm{d} \sim 0.1 \mu \mathrm{m}$.

Due to self-absorption, the recorded scattered intensity $\left(I_{s}\right)$ for any phonon peak depends on the absorbance for a given probed depth. Assuming a flat damage profile, with constant scattered intensity $\left(I_{s, 0}\right)$ versus depth, the absorbance $(\mathbb{A})$ of the Raman signal writes:

$$
\mathbb{A}=-\log \left(\frac{I_{S}}{I_{s, 0}}\right)=\mathbb{A}_{0}+k \exp \left(\frac{E_{G}-\hbar \omega}{E_{U}}\right)
$$

where $\mathbb{A}_{0}$ is a constant absorbance background value, and $\mathrm{k}$ is the Urbach parameter near 1 . We define $I_{s, 0}$ as the total emitted scattered intensity which is considered to be constant over sample depth. The depth dependence of the Raman signal on the damage profile is not taken into account. For a given Raman intensity $\left(\mathrm{I}_{\mathrm{s}, 0}\right)$, the absorbance $(\mathbb{A})$ will depend on $\mathrm{E}_{\mathrm{G}}$ and $\mathrm{E}_{\mathrm{U}}$.

We assume that the Raman scattering cross section is not modified by resonance effects for this photon energy (E). Actually, surface Raman enhanced scattering seems unlikely for such undoped wide band-gap semiconductor at room temperature. At least, the incident photon energy must coincide with a specific defect or impurity level in the band gap, such as for doped semiconductors. However, no abrupt increase in phonon peak intensity was recorded with decreasing band gap for increasing fluence. 
The next step is to correlate the optical gap shrinkage with disorder accumulation, as a function of fluence. Actually, $E_{G}$ decreases versus fluence $(\varphi)$ according to a second-order kinetics process:

$$
E_{G}=E_{G, 0}(1+\sigma \varphi) e^{-\sigma \varphi}+E_{G, \infty}
$$

where $E_{G, 0}=3 \mathrm{eV}$ is the band-gap energy value prior to irradiation, $\sigma=3.2 \times 10^{-14} \mathrm{~cm}^{2}$ is a damage cross section, and $E_{G, \infty}=0.50 \mathrm{eV}$ is the asymptotic value for a-SiC after 4.0-MeV Au ion irradiation (Fig. 1) $[7,8,19]$. Moreover, the Urbach energy is increasing up to an asymptotic value of $\mathrm{E}_{\mathrm{u}, \infty}=0.56$ $\mathrm{eV}$ versus $\varphi$ with a damage cross section of $\sigma^{\prime}=5.6 \times 10^{-13} \mathrm{~cm}^{2}$, with a small initial value $E_{U, 0}$ close to 0 (Fig. 1):

$$
E_{U}=E_{U, \infty}\left(1-e^{-\sigma^{\prime} \varphi}\right)
$$

By substituting Eqs. (3) and (4) in Eq. (2), one is able to calculate the relative absorbed scattered light intensity $\left(1-\frac{I_{s}}{I_{s, 0}}\right)$ versus $\varphi$ for $E=2.3 \mathrm{eV}$. Since $f_{D}=1-A / A_{\text {cryst }}$, is deduced from the integrated areas $(A)$ of the main Raman peaks, as explained above, we use the approximation that $f_{D}$ is proportional to $\left(1-\frac{I_{S}}{I_{s, 0}}\right)$, by assuming that self-absorption is the cause of peak intensity decrease after irradiation. The decrease of Raman peak intensities is a direct evidence of the decay of the crystalline phase with ion fluence in the irradiated material consisting of the crystalline and amorphous phases. No significant broadening of the phonon crystal peaks due to disorder was found. The self-absorption of those peaks is assumed to be the same as the total scattered intensity, since the Raman shift is very small. We neglect the change in reflectance, related to refractive index variation with fluence [22] that would simply give an offset of the curve. The onset of stage I of damage for $\varphi \sim 1 \times 10^{12} \mathrm{~cm}^{-2}$ corresponds to the onset of band-gap narrowing and onset of Urbach energy saturation due to pointdefect build up (Fig. 1). In stage II for $\varphi \geq 3 \times 10^{13} \mathrm{~cm}^{-2}$, the increase of $f_{D}$ corresponds to the onset of absorption for $E \geq E_{G}$, and the saturation for $\varphi \geq 3 \times 10^{14} \mathrm{~cm}^{-2}$ corresponds to the saturation of optical gap in a-SiC.

The disordered fraction can be fitted by using a trial-and-error method by varying the $\mathbb{A}_{0}, k$, and cross section values. The evolution of $\left(1-\frac{I_{s}}{I_{s, 0}}\right)$ versus fluence looks similar to the evolution of disordered fraction measured by Raman spectroscopy by using two different cross sections: $\sigma=1.0 \times 10^{-14} \mathrm{~cm}^{2}$ and $\sigma^{\prime}=2.0 \times 10^{-13} \mathrm{~cm}^{2}$, and the following parameters: $\mathrm{A}_{0}=0.03, \mathrm{k}=1.3, \mathrm{E}_{\mathrm{G}, \infty}=0.50 \mathrm{eV}$, and $\mathrm{E}_{\mathrm{U}, \infty}=0.70$ $\mathrm{eV}$. The background absorbance $\left(\mathbb{A}_{0}\right)$ is rather consistent with the reflectance loss $(R \sim 20 \%)$ at the $\mathrm{SiC} /$ air interface deduced from Fresnel's equation and a refractive index of $n=2.66$ for $E=2.3 \mathrm{eV}$. This yields a background absorbance of $\mathbb{A}_{0}=-\log (0.8) \sim 0.1$ corresponding to the reflectivity of the laser light at the sample surface. The calculated value of $\left(1-\frac{I_{S}}{I_{s, 0}}\right)$ with a scaling factor of 3.2 is shown in Fig. 1 (blue dotted curve). Even though those two cross sections deviate slightly from the least- 
square fits of $E_{G}$ and $E_{U}$ data versus fluence, this evolution can account for the RRI procedure, as discussed above.

For comparison, the $\sigma$ values deduced from RBS/C data for $6 \mathrm{H}-\mathrm{SiC}$ at a $600 \mathrm{~nm}$ depth are of $1.84 \times 10^{-}$ ${ }^{14} \mathrm{~cm}^{2}$ for a single impact model [5] and $3.0 \times 10^{-14} \mathrm{~cm}^{2}$ for the stage II [4]. Fitting the Raman data with the multi-step damage accumulation (MSDA) model yields the damage cross sections of $1.3 \times 10^{-13} \mathrm{~cm}^{2}$ and $1.1 \times 10^{-14} \mathrm{~cm}^{2}$ for stage I and stage II [6], respectively, that are in rather good agreement with the present $\sigma^{\prime}$ and $\sigma$ values, respectively. However, this MSDA analysis is an ad-hoc modelling which does not give any physical explanation of those two cross sections. Fitting the RBS/C data at $600-\mathrm{m}$ depth with the MSDA model (Fig. 1, black dotted curve) gave cross sections of $2.5 \times 10^{-14} \mathrm{~cm}^{2}$ and $3.0 \times 10^{-14} \mathrm{~cm}^{2}$ for stage I and stage II [6], respectively, which are clearly different from those of Raman spectroscopy data. This deviation definitely arises from the different physical processes associated to these two kinds of measurements. RBS/C spectroscopy is based on the scattering of channelled particles in the crystal rows, whereas Raman spectroscopy is based on the inelastic scattering of light by optical phonon modes. The background and saturation values of $f_{D}$ (Fig. 1) are also different due to the different processes involved in those measurements.

\section{CONCLUSION}

In summary, the evolution of the amorphous fraction of heavy-ion irradiated $\mathrm{SiC}$ on the basis of the RRI of Raman spectra is accounted for by the band-gap reduction and Urbach energy increase due to disorder accumulation. The two different stages correspond to the different cross sections of those two processes. In stage I, the Urbach energy increases up to saturation when reaching stage II of the onset of amorphization. The band-gap energy starts to clearly decrease at the end of stage I due to band tailing and saturates when full amorphization is achieved. 


\section{$\underline{\text { References }}$}

[1] M. Ishimaru, I.-T. Bae, Y. Hirotsu, S. Matsumura, and K. E. Sickafus, Structural relaxation of amorphous silicon carbide, Phys. Rev. Lett. 89 (2002) p. 055502.

[2] W. J. Weber, Y. Zhang, and L. Wang, Review of dynamic recovery effects on ion irradiation damage in ionic-covalent materials, Nucl. Instr. Meth. B 277 (2012) pp. 1-5.

[3] F. Gao, and W. J. Weber, Mechanical properties and elastic constants due to damage accumulation and amorphization in SiC, Phys. Rev. B 69 (2004) p. 224108.

[4] X. Kerbiriou, J. M. Costantini, M. Sauzay, S. Sorieul, L. Thomé, J. Jagielski, and J. J. Grob, Amorphization and dynamic annealing of hexagonal SiC upon heavy-ion irradiation: Effects on swelling and mechanical properties, J. Appl. Phys. 105 (2009) pp. 073513-073524.

[5] J. M. Costantini, X. Kerbiriou, M. Sauzay, and L. Thomé, Ion-beam modifications of mechanical and dimensional properties of silicon carbide, J. Phys. D: Appl. Phys. 45 (2012) pp. 465301-465309.

[6] S. Miro, J. M. Costantini, J. Hughet-Garcia, and L. Thomé, Recrystallization of hexagonal silicon carbide after gold ion irradiation and thermal annealing, Philos Mag 94 (2014) pp. 3898-3913.

[7] S. Sorieul, J. M. Costantini, L. Gosmain, G. Calas, J. J. Grob, and L. Thomé, Raman spectroscopy study of heavy-ion-irradiated $\alpha$-SiC, J. Phys.: Condens. Matter 18 (2006) pp. 5235-5251.

[8] S. Sorieul, J-M Costantini, L. Gosmain, G. Calas, J-J Grob, and L. Thomé, Study of damage in ionirradiated $\alpha$-SiC by optical spectroscopy, J. Phys.: Condens. Matter 18 (2006) pp. 8493-8502.

[9] W. Jiang, Y. Zhang, and W. J. Weber, Temperature dependence of disorder accumulation and amorphization in Au-ion-irradiated 6H-SiC, Phys. Rev. B 70 (2004) p. 165208.

[10] M. Gorman, and S. A. Solin, Direct evidence for homonuclear bonds in amorphous SiC, Solid State Commun. 15 (1974) pp. 761-765.

[11] W. Bolse, Formation and development of disordered networks in Si-based ceramics under ion bombardment, Nucl. Instr. and Meth. B 141 (1998) pp. 133-139.

[12] R. Menzel, K. Gärtner, W. Wesch, and H. Hobert, Damage production in semiconductor materials by a focused $\mathrm{Ga}^{+}$ion beam, J. Appl. Phys. 88 (2000) pp. 5658-5661.

[13] A. Pérez-Rodriguez, Y. Pacaud, L. Calvo-Barrio, C. Serre, W. Skorupa, and J. R. Morante, Analysis of ion beam induced damage and amorphization of $6 \mathrm{H}-\mathrm{SiC}$ by Raman scattering, J. Electron. Mater. 25 (1996) pp. 541-547.

[14] K. Karch, P. Pavone, W. Windl, O. Schütt, and D. Strauch, Ab initio calculation of structural and lattice-dynamical properties of silicon carbide, Phys. Rev. B 50 (1994) pp. 17054-17063.

[15] M. H. Brodsky, and M. Cardona, Local order as determined by electronic and vibrational spectroscopy: Amorphous semiconductors, J. Non-Crystal. Solids 31 (1978) pp. 81-108.

[16] R. Zallen, The Physics of Amorphous Solids (Wiley, New York, 1983). 
[17] S. R. Elliott, Physics of Amorphous Materials, $2^{\text {nd }}$ edition (Longman, 1983).

[18] N. F. Mott, and E. A. Davis, Electronic Processes in Non-Crystalline Materials, $2^{\text {nd }}$ edition (Clarendon, Oxford, 1979).

[19] S. Sorieul, X. Kerbiriou, J. M. Costantini, L. Gosmain, G. Calas, C. Trautmann, Optical spectroscopy study of damage induced in 4H-SiC by swift heavy ion irradiation, J. Phys.: Condens. Matter 24 (2012) pp. 125801-125808.

[20] J. I. Pankove, Optical Processes in Semiconductors (Prentice-Hall, Engelwood Cliffs, 1971).

[21] M. Beaudoin, A. J. G. DeVries, S. R. Johnson, H. Laman, and T. Tiedje, Optical absorption edge of semi-insulating GaAs and InP at high temperatures, Appl. Phys. Lett. 70 (1997) pp. 3540-3542.

[22] E. Wendler, A. Heft, U. Zammit, E. Glaser, M. Marinelli, and W. Wesch, Sub-gap optical properties of ion implanted SiC, Nucl. Instr. Meth. B 116 (1996) pp. 398-403. 
Fig. 1: Relative absorbed scattered light intensity $\left(1-\frac{I_{S}}{I_{s, 0}}\right)$, for a photon energy $E=2.3 \mathrm{eV}$ (left scale with a scaling factor of 3.2, blue dotted curve), disordered fraction $\left(f_{D}\right)$ deduced from Raman spectra (full circles) and RBS/C spectra at 600-nm depth (open circles) (left scale), and optical gap $\left(E_{G}\right)$ deduced from UV-visible absorption spectra (right scale) for 4.0-MeV Au ion irradiation [7, 8], as a function of fluence. The solid curve is the fit of $E_{G}$ values with Eq. (3). The dashed curve is the fit of $E_{U}$ values with Eq. (4). The blue dotted curve is the fit of $f_{D}$ Raman data using Eqs. (2)-(4). The black dotted curve is the fit of $f_{D} R B S / C$ data with the MSDA model [6]. The vertical dashed line divides the first and second stages of damage. The horizontal arrows mark the values of laser excitation $(E=2.3$ $\mathrm{eV})$ and initial band gap value $\left(\mathrm{E}_{\mathrm{G}, 0}=3 \mathrm{eV}\right)$.

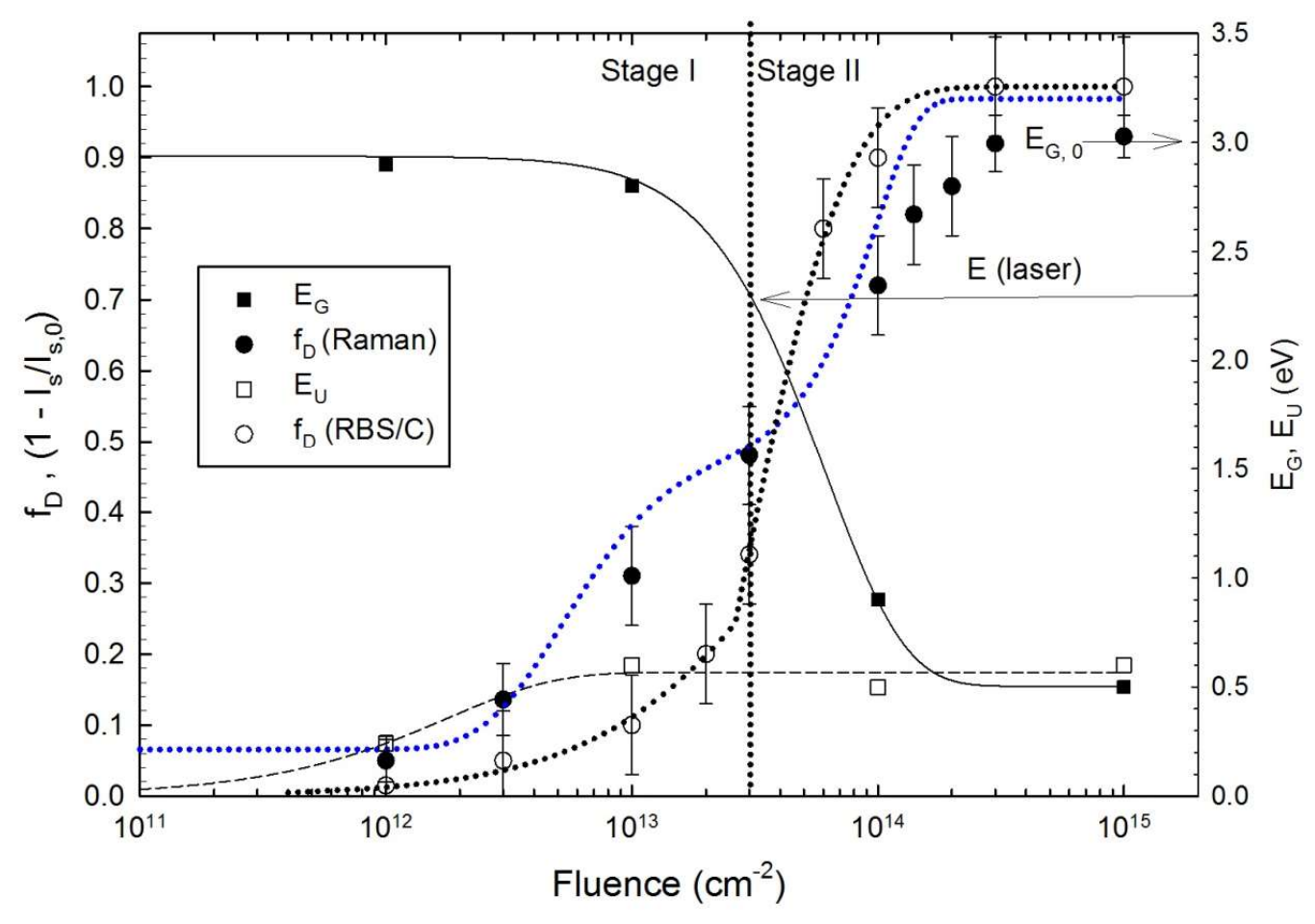

